\title{
Use of nonpharmacological
methods while taking blood \\ Use of nonpharmacological
methods while taking blood sample from children
}

Çocuklarda kan alma işlemi sirasinda uygulanan nonfarmakolojik yöntemlerin kullanımı ${ }^{1}$

\author{
Meltem Kürtüncü ${ }^{2}$ \\ Seda Davas ${ }^{3}$
}

\begin{abstract}
The aim of this review is to examine the literature on the effect of non-pharmacological methods on children's anxiety, pain level and parental satisfaction during blood collection.

There are 2 doctoral theses and 12 master's theses at NTC National Thesis Center on pain management during the blood collection process in children. Numerous publications and articles have been searched and it is observed that nonpharmacological methods applied during the blood collection process generally have positive effects on pediatric patients and their families.

It is thought that non-pharmacological techniques applied during the blood collection process will reduce the anxiety, fear and pain in children and increase the satisfaction of the family and the child in nursing care and their compliance with thenonpharmacologic methods during blood collection in children is discussed.
\end{abstract}

Keywords: Pain, Anxiety, Fear, Taking a blood sample, Child.

(Extended English summary is at the end of this document)

\section{Özet}

$\mathrm{Bu}$ derleme, çocuklara kan alma işlemi sırasında uygulanacak olan nonfarmakolojik yöntemlerin çocuklardaki anksiyete, ağr1 düzeyi, ebeveyn memnuniyetine etkisini belirlemek amaciyla yapılmış olan literatürü incelemek amaçlanmıştır. Cocuklarda kan alma işlemi sırasında hissedilen ağrı yönetimiyle ilgili YÖK Ulusal Tez Merkezi'nde 2 adet doktora tezi ve 12 adet yüksek lisans tezi bulunmaktadır. Konuyla ilgili sayısız yayın ve makale taranmış olup, genel itibariyle kan alma işlemi sırasında uygulanan nonfarmakolojik yöntemlerin çocuk hastalar ve aileleri üzerinde olumlu etkiler yaptığ1 gözlenmiştir.

Kan alma işlemi sirasinda uygulanan nonfarmakolojik tekniklerin çocuklarda oluşan anksiyete, korku ve ağriyı azaltmasının yanında ailenin ve çocuğun hemşirelik bakımında memnuniyetini ve tbbi işlemlere olan uyumunu artırarak, tıbbi işlem korkusuna bağlı oluşan psikosomatik komplikasyonların kısa ve uzun dönem sonuçlarını olumlu yönde etkileyeceği düşünülmektedir. Bu derlemede, çocuklarda kan alma işlemi sırasında nonfarmakolajik yöntemlerin kullanımından bahsedilmiştir.

Anahtar Kelimeler: Ağrn, Anksiyete, Korku, Kan alma, Çocuk.

\footnotetext{
${ }^{1}$ Bu çalışma 29 Kasım- 1 Aralık 2018 tarihlerinde 3.Uluslararası Sağlık Bilimleri Kongresi'nde Poster olarak sunulmuştur. ${ }^{2}$ Assoc. Prof. Dr., Bülent Ecevit University, Faculty of Health Sciences Nursing Department, meltem.kt@,beun.edu.tr (iD) Orcid ID: 0000-0003-3061-5236

${ }^{3}$ Bülent Ecevit University, Institute of Health Sciences, Department of Child Health and Diseases Nursing, davasseda93@gmail.com (iD Orcid ID: 0000-0002-5689-8556
} 
Kürtüncü, M., \& Davas, S. (2020). Çocuklarda kan alma işlemi sırasında uygulanan nonfarmakolojik yöntemlerin kullanım. Journal of Human Sciences, 17(2), 710-719. doi:10.14687/ihs.v17i2.5785

\section{Giriş}

Çocuklarda soyut düşünme ve neden sonuç yeteneği gelişmemiş hastalık örüntüleri yetişkinlerden farklıdır. Her zaman özel bakım gereksinimi olan, yaşam deneyimleri, zihinsel gelişimler ve kendilerini sözel olarak ifade etme becerileri yetersiz olduğundan stresli yaşam olaylarıyla baş etme yetenekleri sinırlı bireylerdir (Törüner ve Büyükgönenç, 2017; Conk ve ark. 2013). Hastalık onlar için diş faktörlere bağlı, ağr1 ve stres kaynağı niteliği taşımakta ve yaptıkları kötü davranış için ceza niteliği taşımaktadır (Törüner ve Büyükgönenç, 2017; Conk ve ark., 2013; Teksöz ve Ocakçı, 2014). Hastane ise çocuklar için yabancı ortam, tanımadığı kişiler, bağımlı olma, kontrol ve mahremiyetin kaybı, acı veren işlemler, rutinlerinin bozulması, ameliyat, ağrı, sakat kalma, ölüm, aileden, arkadaşlardan, önemli kişilerden ayrılma gibi anlamlar taşımaktadır (Conk ve ark., 2013).

Hastane çocuğun doğumundan itibaren takipler için veya hastalıklar sirasında s1k sik başvurulan yer olup kan alma, enjeksiyon ve aşı uygulaması gibi ağrılı medikal prosedürler yapılmaktadır (İnal ve Canbulut , 2015; Gündüz ve ark., 2016). Hastane ortamında uygulanan invaziv girişimler çocuklar için ağrı, endişe ve korkuya neden olmaktadır (Gündüz ve ark., 2016; Cura ve ark., 2018). Çocuklar hastaneye yatış ve uygulanan invaziv girişimler nedeniyle anksiyete, regresyon, bağlanma ve ayrilış problemleri, keder, hiperaktivite, apati, kendi içine çekilme, daha önce kazandıkları bazı becerileri kaybetme gibi tepki gösterebilirler (Başbakkal ve ark., 2010; Conk ve ark., 2013).

Uluslararası Ağrı Araştırma Derneği Taksonomi Komitesi (International Association for the Study of Pain=IASP) ağrıy "vücudun belirli bir bölgesinden kaynaklanan, doku hasarına bağlı olan veya olmayan, kişinin geçmişteki deneyimlerinden etkilenen hoş olmayan deneyim" şeklinde tanımlamıştır (Törüner ve Büyükgönenç, 2017; Cırık ve Efe, 2014).Beşinci yaşam bulgusu olarak kabul edilen ağrı subjektif, psikolojik yönleri bir arada bulunduran ve fiziksel, emosyonel dişsal faktörlerden etkilenen karmaşık bir tablo, çok yönlü bir deneyimdir. İnsanlar arasında ağr1 algısı farklılıklar gösterir, hatta aynı kişide zaman içinde değişikliğe de uğrayabilmektedir (Koç Özkan ve Balc1, 2018; Eti Aslan, 2002; Emre Yavuz,2011).Bu karmaşıklığ1 en çok yaşayan gruplardan biri de kendini ifade edemeyen çocuklardır (Koç Özkan ve Balc1, 2018; İnal ve Canbulut, 2015).

Çocukların yaşadığı ağrı, fiziksel, hormonal, mental ve sosyal gelişimini, ebeveyn veya ailedeki diğer kişilerin yaşantılarını, beslenme ve boşaltım sistemini etkilemekte olup psikosomatik bozukluklara, tıbbi işlem korkusuna ve tedavinin aksamasına neden olmaktadır (Özveren ve Uçar, 2009; Yayan ve Zengin,2018; Çelik, 2016). Ayrica farmakolojik veya farmakolojik olmayan girişimleri belirlemek, tanı konulmasına yardım etmek, cerrahi ya da diğer komplikasyonları gözlemlemek amacı ile ağrının değerlendirilmesi oldukça önemlidir (Törüner ve Büyükgönenç, 2017; Özveren ve Uçar, 2009).Bu nedenle ağrının değerlendirilmesi, var olan ağrının giderilmesi, oluşabilecek olan ağrının en aza indirilmesi gerekmektedir (Başbakkal veark., 2010; Göl ve Onarıc1, 2015). Çocukların ağrısını gidermek ve yaşam kalitesini arttırmak hemşirelik bakımının temel hedeflerinden birisiolup 1989 yllinda Donna Wong atravmatik bakım felsefesinde temel ilke olarak ağrı kontrolünü tanımlamıştır(Teksöz ve Ocakçı, 2014).Dünya Sağlık Örgütü (DSÖ)'ne göre ağrının hafifletilmesi en temel haktır (İnan, 2017).Çocuklarda ağrı kontrolü ekip işidir. Ağrı kontrolünde hemşireyi diğer ekip üyelerinden ayıran ve önemli kılan noktalar; hemşirenin hastayla uzun süre birlikte olması, hastanın önceki ağrı deneyimlerini ve ağrıyla baş etme yöntemlerini öğrenmesi, gerektiğinde bunlardan yararlanması, ağrı ile başa çıkma stratejilerini hastaya öğretmesi, planlanan tedaviyi uygulaması, etkilerini ve sonuçlarını izlemesi, empatik yaklaşımı sağlamasıdır (Başbakkal ve ark., 2010; Eti Aslan ve ark., 2003).Hemşirelerin, çocuklarda invaziv girişimlere bağlı ağrının etkilerini azaltmak; fiziksel ve emosyonel etkilerini gidermek için ağrıy etkili bir şekilde yönetebilmeleri gerekmektedir (Cura ve ark., 2018).

Ağrının yönetim şekli planlanırken ağrının tipi, yeri, şiddeti, hastalığın özellikleri, hastanın yaşı, fiziki durumu ve tıbbi olanaklar dikkatle incelenmeli ve uygun olan yöntem seçilmelidir (Emir ve Cin, 2004). 
Kürtüncü, M., \& Davas, S. (2020). Çocuklarda kan alma işlemi sırasında uygulanan nonfarmakolojik yöntemlerin kullanım. Journal of Human Sciences, 17(2), 710-719. doi:10.14687/ihs.v17i2.5785

\section{Ağrının değerlendirilmesinde temel ilkeler;}

1. Çocuğa ağrısı ve yeri ile ilgili soruların sorulması,

2. Ağrı ölçeklerinin kullanılması,

3. Davranışsal ve fizyolojik değişkenlerin değerlendirilmesi,

4. Ağrı nedeninin belirlenmesi

5. Hemşirelik bakımına ebeveynlerin katılımının sağlanması

Ağrı yönetiminde farmakolojik ve nonfarmakolojik yöntemler kullanılmaktadır (Cırık ve Efe, 2014; Özveren ve Uçar, 2009; Çelik, 2016).Çocuklarda ağrn kontrolünde yer alan ilaçlar üç grupta incelenir:

- Opioid analjezikler,

- Opioid olmayan analjezikler ve

- Lokal analjezikler (Törüner ve Büyükgönenç, 2017; Conl ve ark., 2013; Özveren ve Uçar, 2009).

İlaçlarla ağr1 kontrolü çabuk etki göstermesi ve kolay uygulanabilir olması nedeniyle en yaygın kullanılan tedavi yöntemidir(Cırık ve Efe, 2014; Emir ve Cin, 2004). Ancak invaziv işlemler sırasında kullanılan farmakolojik ilaçlar vazokontriksiyona neden olarak damara girme işleminde başarıyı azalmakta,işlem süresini uzatmakta ve vücuda zarar yan etkilere neden olmaktadır (İnal ve Canbulut, 2015; Koç Özkan ve Balc1, 2018).Non- farmakolojik yöntemler vücudun doğal morfini olan endorfinlerin salınımını arttırarak ağrının giderilmesini sağlarlar ve vücuda zararlı yan etkileri yoktur. Nonfarmakolojik yöntemler invaziv değildir, ucuzdur, güvenilirdir, yan etkisi yoktur ve hemşirenin bağımsız uygulamalarındandır (Törüner ve Büyükgönenç, 2017; İnal ve Canbulut , 2015).

Non-farmakolojik yöntemler; destekleyici yöntemler (psikososyal), fiziksel yöntemler ve bilişsel/davranışlar yöntemler olarak üç grupta toplanırlar (İnal ve Canbulut, 2015; Arslan ve Çelebioğlu, 2004; Yıldız, 2014).

- Destekleyici yöntemler; video izleme, kitap okuma ve işlem sırasında ailenin yanında bulunması gibi teknikleri kapsar (İnal ve Canbulut, 2015; Arslan ve Çelebioğlu, 2004; Yıldız, 2014).

- Fiziksel yöntemler arasında; sıcak- soğuk uygulama, pozisyon verme, buzzy aygitı pozisyon verme gibi uygulamalar yer almaktadır(İnal ve Canbulut, 2015; Arslan ve Çelebioğlu, 2004).

- Bilişsel/davranışsal yöntemler ise; ağrının algısal, duyusal, davranışsal boyutunu kapsar ve gevşeme, dikkati başka yöne çekme, hipnoz gibi yöntemleri içerir. Dikkati başka yöne çekme yöntemleri arasında dijital oyun oynatma, çizgi film izletme, kaleydeskop kullanma, sanal gerçeklik gözlüğü, balon izletme, müzik dinletme gibi birçok uygulama yer almaktadır (İnal ve Canbulut, 2015; Yıldız, 2014).

\footnotetext{
Amaç

$\mathrm{Bu}$ derleme, çocuklara kan alma işlemi sırasında uygulanacak olan nonfarmakolojik yöntemlerin çocuklardaki anksiyete, ağrı düzeyine etkisini belirlemek amacıyla yapılmış olan literatürü incelemek amaçlanmıştır.

\section{Yöntem}

Çalışmanın evrenini Pubmed, Scopus, Google Scholar, EBSCOhost, ScienceDirect, Yök Tez arama motorları kullanılarak erişilen, "ağrı, anksiyete, korku, kan alma, çocuk, kan alımı" anahtar kelimeler İngilizce ve Türkçe yazılarak, herhangi bir tarih sınırlaması yapılmadan konu ile igili elde edilen çalışmalar oluşturmuştur.
} 
Kürtüncü, M., \& Davas, S. (2020). Çocuklarda kan alma işlemi sırasında uygulanan nonfarmakolojik yöntemlerin kullanımı. Journal of Human Sciences, 17(2), 710-719. doi:10.14687/ihs.v17i2.5785

\section{Bulgular}

Çocuklarda kan alma işlemi sırasında hissedilen ağrı yönetimiyle ilgili YÖK Ulusal Tez Merkezi'nde iki adet doktora tezi ve 12 adet yüksek lisans tezi bulunmaktadır. Konuyla ilgili sayısız yayın ve makale taranmış olup, genel itibariyle kan alma işlemi sırasında uygulanan nonfarmakolojik yöntemlerin çocuk hastalar ve aileleri üzerinde olumlu etkiler yaptığı gözlenmiştir.

\section{Buzzy Ayg1t1}

Dr. Amy Baxter tarafindan ağrıyı azaltmak üzere geliştirilmiştir.Sert plastikten yapılmış, pil ile çalışan ve arıya benzeyen bu cihaz, uygulama yapılacak bölgeye lokal olarak soğuk ve titreşim sağlanmaktadır (Şahin, 2013).

Redfern ve arkadaşlarının 3-18 yaş grubu 50 çocuk ilekan alma işlemi sırasında buzzy uygulamasının ağrı ve kayg1 seviyelerine etkisini araştırmak için yapmış olduğu randomize kontrollü çalışmada buzzy aygitının kan alma işlemi sırasında ağrıyı azalttığını, ancak işlem öncesi kaygıyı etkilemediği bulunmuştur (Redfern ve ark., 2018).6-12 yaş grubu çocuklarda kan alma işlemi sırasında buzzy aygitının ağr1 ve kayg1 düzeyine etkisinin incelendiği randomize kontrollü çalışmada, buzzy aygıtının kan alma işlemi sırasında ağriyı ve kaygiyı azalttığı saptanmıştır (İnal ve Kelleci, 2012).

Kearl ve arkadaşlarının yapmış olduğu bir ay ve 21 yaş grubu arasında J-tip® ve Buzzy® ile randomize kontrollü çalışmada, iki deney grubu oluşturmuş ve birinci gruba sadece J-tip ${ }^{\circledR}$ (lidokainin deri altından verilmesi için iğnesiz bir cihaz) uygularken, ikinci gruba ise J-tip ${ }^{\circledR}$ ve Buzzy ${ }^{\circledR}$ aygıtını uygulamıştır. Araştırma sonucunda J-tip ${ }^{\circledR}$ ve Buzzy® aygıtı uygulanan hastalarda ağrı düzenin istatistiksel olarak daha az olduğu saptanmıştır (Kearl ve ark., 2015).Erdoğan'ın 7-12 yaş grubu 142 çocuk ile sanal gerçeklik gözlüğü, buzzy ayg1tı, dikkati başka yöne çekme kartları ve kontrol grubu ile yapmış olduğu randomize kontrollü çalışmada üç farklı yöntemin ağriyı ve anksiyeteyi azaltmada etkili olduğunu saptamıştır (Erdoğan, 2018).

İncelenen çalışmalar sonucunda buzzy aygıtının kan alma işlemi sırasında ağrıyı azaltmada etkili olduğu saptanmış olsa da bu konu ile ilgili daha çok çalışmaya ihtiyaç vardır.

\section{Çizgi Film İzletme}

Stephenson tarafindan "hareketlendirme sanatı" olarak kabul edilen çizgi filmler çocukları ekrana bağlayan en etkili programlardır (Saraç, 2018).Görsel ve işitsel uyarıları beraber vererek aktif olarak dikkati başka yöne çekmeyi sağlayan bu yöntem birçok duyunun aynı anda harekete geçmesini sağlayarak ilginin oluşacak ağrıdan başka durumlara yöneltilmesini sağlar (Erdoğan, 2018).

Acil servis ünitesinde 3 ile 18 yaş arası 44.000 çocuk muayene ve ağrllı işlemler sırasında işlem öncesi 5 dakika çocuklara çizgi film izletmenin etkisinin araştırıldığı çalşmada çizgi film izlemenin ağrı algısının azalmasında etkili olduğunu saptanmıştır (Downey ve Zun, 2012).Lobo ve Umarani, damar yolu açma sırasında 3-6 yaş arası 60 çocukla yaptıkları randomize kontrollü çalışmada, kontrol gruptaki çocuklara rutin damar yolu açma prosedürü uygulamış, deney grubundaki çocuklara ise, işlem sırasında çizgi film izletmiştir. Çalışma sonucunda çizgi film izlemenin ağrıyı azaltmada etkili olduğunu saptanmıştır (Lobo ve Umarani, 2013),

Yoo ve arkadaşlar1 3-7 yaş grubu 20 deney ve 20 kontrol grubu olmak üzere 40 çocuk ile venöz kan alımı sırasında çizgi film izlettirme yöntemi kullanarak yapmış olduğu çalışma sonucunda çizgi film izleyen grubun ağrı puanı, kan kortizol düzeyi ve kan glikoz düzeyleri kontrol grubuna göre düşük bulunmuştur (Yoo ve ark., 2011).

Yapılan çalışmalar sonucunda çizgi film izlemenin kan alma işlemi sırasında ağrıyı azaltmada etkili olduğu ve etkili bir şekilde kullanılabileceği saptanmıştır.

\section{Sanal Gerçeklik Gözlüğü}

Sanal gerçeklik (Virtual Reality Glass) başka bir dünyayı ziyaret ettiği hissi veren, hastay1 gerçek hayattan izole etmek için hastaya takılan bir başlıkla hastanın gözlerine lens yaklaştırılarak bilgisayardan alınan görüntülerin izletildiği yöntemdir (İnal ve Canbulut, 2015).Genellikle bir gözlük ya da başlıkla uygulanır.Ayrıca hastaya kulaklık takılması yoluyla çevresel sesleri algılaması da engellenmektedir ve rahatlatıcı seslerin dinlemesi sağlanmaktadır. Teknolojinin gelişmesiyle birlikte özellikle yanıklı hastalarda dikkati yönlendirme yöntemi olarak kullanımı artmıştır 
Kürtüncü, M., \& Davas, S. (2020). Çocuklarda kan alma işlemi sırasında uygulanan nonfarmakolojik yöntemlerin kullanım. Journal of Human Sciences, 17(2), 710-719. doi:10.14687/ihs.v17i2.5785

Venöz kan alımı sırasında kullanılan sanal gerçeklik gözlüğünün hissedilen ağrı üzerine etkisinin incelediği 80 çocuk kontrol ve deney grubu mevcut olarak yapılmış olan çalışmada sanal gerçeklik gözlügünün etkili değerlendirilmiştir. Çalışma sonucu sanal gerçeklik gözlügünün ağrıyı azaltmada olduğunu saptanmıştır (Göksu, 2017).7-19 yaş grubu çocuklarda venöz port katateri takımı sırasında sanal gerçeklik gözlüğü kullanılan ve kontrol grubu oluşturarak yapılmış olan çalışma sonucu sanal gerçekliğin ağrilı tıbbi prosedürler sırasında dikkat dağıtmak için yararlı bir araç olabileceğini saptamışlardır (Gershon ve ark., 2004).

Das ve arkadaşlarının yapmış olduğu randize kontrollü pilot çalışmada 5 ile 18 yaş arası çocukların yanık yaralarının pansumanlar değişimi sırasında sanal gerçeklik gözlüğünün ağrıyı azaltmada etkili olduğu saptanmıştır (Das ve ark., 2005).Hastanede yatan 6-19 yaş grubu yanıklı 54 çocuğa analjeziye ek bir yöntem olarak sanal gerçeklik kullanıldığı randomize kontrollü çalışma sonucunda bireylerin sanal gerçeklik uygulaması sırasında ağr1 derecelendirmelerinde önemli düşüş olduğu belirlenmiştir (Schmitt ve ark., 2011).

Sanal gerçeklik gözlüğünün kan alma ve diğer ağrılı işlemler sırasında ağrıyı azaltmada etkisini değerlendiren çok az çalışma mevcut olup daha çok çalışmaya ihtiyaç vardır.

\section{Müzik Dinletme}

Müzik, dikkati ağrı dışında bir uyaranda odaklaşmasını sağlayarak ve endorfin salgılanmasını arttırarak tarih boyunca tedavi edici ve iyileştirici olarak görülmüştür.Kullanımı kolaydır ve dikkatin ağrı dışında farklı bir uyaranda yoğunlaşmasını sağlar.Ayrıca bireyin ağrı toleransını artırır ve bireyi rahatlatır (Sülü Uğurlu, 2017).

4-13 yaş grubu 108 çocukta venöz kan alımı öncesi, sırası ve sonrasında müzik dinletilmesi sonucunda deney grubunda kontrol gurubuna göre ağr1 ve stres düzeyi daha düşük bulunmuştur (Caprilli ve ark.,2007).Venöz girişim yapılan başkabir çalışmada 5-12 yaş grubu çocuklar üç gruba ayrilmıştır. Bir gruba lokal anestetik krem, bir gruba plasebo ve bir gruba da müzik dinletme metoduyla dikkati başka yöne çekme tekniği uygulanmış ve çalışma sonucunda müzik dinleyen ve lokal anestezik krem kullanılan çocuklarda ağrı puanının plasebo grubundan anlamlı şekilde düşük olduğu saptanmıştır (Balan ve ark., 2009).

Flebetomi sırasında 6-12 yaş grubu çocuklarda, dikkat dağıtıcı kartlar, müzik dinletme, balon şişirme ve kontrol olarak dört gruba ayırarak yapmış olduğu çalışma sonucu üç farklı yöntemin de ağr1 ve kaygı1y azalmada etkili olduğunu saptamıștır (Şahiner ve Bal, 2016).Müzik uzun yıllardır hemşireler tarafindan ağrıyı azaltmada güvenle kullanılabilen bir yöntemdir.

\section{Video Oyunu}

Crevatin ve arkadaşlarının, 4-13 yaş grubu 200 çocuk ile yapmış olduğu çalışmada, çocukların yarısı elde tutulan bir bilgisayarda Angry Birds oynatılan ve diğer yarısının ise ikinci bir eğitimli hemşire tarafindan dikkati dağıtmak amacı ile kendilerine şark1 söyleyen, kitap okuyan, kabarcıkları patlatan veya kuklalarla oynatılan çocuklar olmak üzere ikiye ayrılmıştır. Çalışma sonucu video oyunu oynayan çocukların ağrı düzeyi diğer çocuklara göre daha düşük saptanmıştır (Crevatin ve ark., 2016).

İnan, 6-10 yaş grubu 180 çocuk ile üç deney ve bir kontrol grubu olmak üzere randomize kontrollü bir çalısma yapmıştır. Birinci grubu; işlem sırasında çizgi film izletilen çocuklar, ikinci grubu; video oyunu oynatılan çocuklar, üçüncü grubu; ebeveynleri tarafindan konuşularak dikkati başka yöne çekilen çocuklar, dördüncü grubu rutin kan alma işlemi uygulanan çocuklar oluşturmuştur. Çalışma sonucu; üç farklı yöntemin ağrıyı ve anksiyeteyi azaltmada etkili ancak video oyunu ağrıyı ve anksiyeteyi azaltmada daha etkili olduğu saptanmıştır (İnan, 2017).

Minute ve arkadaşları,4-10 yaş arası 97 çocukla iğneli uygulamalar sırasında yaptıkları çalışmada kontrol grubuna sadece EMLA krem uygulamış diğer gruba ise EMLA krem ve video oyunu oynatılmış ve sonuç olarak video oyununun ağr1 seviyesinde herhangi bir farklılık yaratmadığ1 saptanmiştır (Minute ve ark., 2012).

Yapılan literatür incelemesi sonucu video oyunu kan alma işlemi sırasında ağrıyı azaltmada etkili olduğu saptanmış olsa da bu konu ile ilgili daha çok çalışmaya ihtiyaç vardır. 
Kürtüncü, M., \& Davas, S. (2020). Çocuklarda kan alma işlemi sırasında uygulanan nonfarmakolojik yöntemlerin kullanım. Journal of Human Sciences, 17(2), 710-719. doi:10.14687/ihs.v17i2.5785

\section{Kaleydeskop Kullanımı}

Çiçek dürbünü veya kaleydoskop, içine bakıldığında ışı̆̆ın yansımasıyla oluşan ve dürbün hareket ettirildikçe sürekli değişen renkli desenler görülen bir aygıttır (İnal ve Canbulut, 2015).

Karakaya ve Gözen,7-12 yaş grubu deney ve kontrol grubu oluşturarak 144 çocuk ile kan alma sırasında çiçek dürbünü kullanılarak dikkatin başka yöne çekilmesinin hissedilen ağrı düzeyine etkisini belirlemek amacıyla yapmış oldukları çalısma sonucunda ağrıyı azaltmada çiçek dürbünü ile dikkatin başka yöne çekilmesinin etkili olduğu saptanmıştır (Karakaya ve Gözen, 2012). Okul çağ1 çocuklarda kan alma işlemi sırasında kaleydeskop kullarak yapılan çalışma sonucunda kaleydeskopun ağrıyı etkili bir şekilde azalttığı saptanmıştır (Güdücü Tüfekçi ve ark., 2009).

7-11 yaş grubu çocuklarda yapılan randomize kontrollü çalışmada dikkati başka yöne çekme kartları ve kaleydeskop kullanmışlardır. Yapılan çalışma sonucunda dikkat dağıtıcı kartların kaleydeskopa göre hissedilen ağrıyı azaltmada daha etkili olduğu saptanmıştır (Canbulut ve ark., 2014).

Elde edilen çalışma verilerine göre kaleydeskop ağrıyı azaltmada kullanılan etkin bir araçtır.

\section{Dikkati Başka Yöne Çekme Kartlanı}

Dikkati başka yöne çekme kartları, "çeşitli gizli resim ve desenleri içeren resimli kartlardan oluşmaktadır. Bu gizli resim ve desenler çocuğun ancak dikkatli bir şekilde kartları incelemesi ile görebileceği niteliktedir. İşlem sırasında çocuğa kartlara odaklanması ve ilgili soruları cevaplaması söylenir (İnal ve Canbulut,2015).

6-12 yaş çocuklarda venöz kan örneği alma işlemi sırasında oluşan ağriyı azaltmak için uygulanan, dikkati başka yöne çekme kartları ve kaleydoskop yöntemlerinin etkisini belirlemek amacıyla yapılan çalışma sonucu deney gruplarının ağrı puanları arasında ise anlamlı fark olmadığı iki yöntemin de ağrıyı azaltmada etkili olduğu görüldü (Semerci, 2017). İnal ve Kelleci’nin kan alma sırasındaki işlemsel ağrı ve kaygıyı azaltmada dikkati başka yöne çekme kartlarının etkisini incelemek için deney ve kontrol grubu oluşturarak yapmış olduğu çalışma sonucu deney grubu, kan alma işlemi sırasında kontrol grubundan anlamlı olarak daha düşük ağrı seviyelerine sahipti. Ayrıca deney grubu kontrol grubundan anlamlı olarak düşük kaygı düzeylerine sahip olduğu saptanmıştır (İnal ve Kelleci, 2012).

Canbulut ve arkadaşlarının 7-11 yaş grubunda flebetomi sırasında çocukların ağrı ve anksiyete rahatlaması üzerine iki farklı distraksiyon yöntemi, distraksiyon kartları ve kaleydoskop kullanarak yapmış olduğu çalışma sonucu distraksiyon kartı grubu, tüm gruplar arasında en düşük ağrı seviyesine ve en düşük kaygı düzeyine sahip olduğu sonucuna varılmıştır (Canbulut ve ark., 2014).

Literatür taraması sonucunda dikkati başka yöne çekme kartlarının invaziv işlemler sırasında ağrıyı ve kayg1yı azaltmada güvenle kullanılabilecek bir yöntem olduğu sonucuna varılmıştır.

\section{Sonuç}

Yapılan çalışmalar, kan alma işlemi sırasında uygulanan nonfarmakolojik tekniklerin çocuklarda oluşan anksiyete, korku ve ağrıyı azaltmasının yanında ailenin ve çocuğun hemşirelik bakımında memnuniyetini ve tıbbi işlemlere olan uyumunu artırarak, tıbbi işlem korkusuna bağlı oluşan psikosomatik komplikasyonları kısa ve uzun dönem sonuçlarını olumlu yönde etkilediğini göstermiştir. Bu yöntemlerin çocuklarda kan alma işlemi sırasında kullanımının yaygınlaştırılması gerektiği düşünülmektedir.

\section{Kaynaklar}

Arslan S, Çelebioğlu A. (2004). Postoperatif ağrı ve yönetimi ve alternatif uygulamalar. Uluslararası Insan Bilimleri Dergisi, 1303-5134.

Balan R, Bavdekar SB, Jadhav S. (2009). Can Indian classical instrumental music reduce pain felt during venepuncture? Indian Journal of Pediatrics, 76, 469-473. 
Kürtüncü, M., \& Davas, S. (2020). Çocuklarda kan alma işlemi sırasında uygulanan nonfarmakolojik yöntemlerin kullanım. Journal of Human Sciences, 17(2), 710-719. doi:10.14687/ihs.v17i2.5785

Başbakkal Z, Sönmez S, Celasin N, Esenay F. (2010). 3-6 yaş grubu çocuğun akut bir hastalık nedeniyle hastaneye yatışa karşı davranışsal tepkilerinin belirlenmesi. Uluslararası Insan Bilimleri Dergisi, 7(1), 456-468.

Canbulut N., İnal S., Sözmezer H. (2014). Efficacy of distraction methods on procedural pain and anxiety by applying distraction cards and kaleidoscope in children. Asian Nursing Research, 8(1), 23-28.

Caprilli S, Anastasi F, Grotto RPL, Abeti MS, Messeri A. (2007). Interactive music as a treatment for pain üand stress in children during venepuncture: a randomized prospective study. Journal of Developmentale Behavioral Pediatrics, 28(5), 399-403.

Çelik S. (2016). Yoğun bakım hastalarında ağr1 yönetimi. Yoğun Bakım Hemşireliği Dergisi, 20(1), 1-8.

Cirık V, Efe E. (2014). Yoğun bakım ünitesinde ağrı ve hemşirenin rolü. Yoğun Bakım Hemşirelĭgi Dergisi, 18(1), 15-21.

Conk, Z., Başbakkal, Z., Bal Yılmaz, H., Bolış1k, B., (2013). Pediatri Hemşirelĭgi, S: 893-910. Ankara: Akademisyen Tip Kitabevi.

Crevatin F., Cozzi G., Braido E., Bertossa G., Rizzitelli P., Lionetti D., Matassi D., Calusa D., Ronfani L., Barbi E. (2016). Hand-held computers can help to distract children undergoing painful venipuncture procedures. Acta Paediatr. Aug;105(8), 930-4. doi: 10.1111/apa.13454

Cura Ş, Oğul T, Kurt F. (2018). Pediatrik Yaş Gruplarında Akut Ağrının Giderilmesinde Kullanılan Tamamlayıcı ve Alternatif Tip Uygulmaları.Zeynep Kamil T⿰р Bülteni, 49(1), 126-129.

Downey VA., Zun LS. (2012) The Impact of Watching Cartoons for Distraction During Painful Procedures in the Emergency Department. Pediatric Emergency, 28(10): 1033-1035. doi:10.1097/PEC.0b013e31826cac1a

Emir S, Cin Ş. (2004). Çocuklarda ağrı: değerlendirme ve yaklaşım. Ankara Üniversitesi Tipp Fakültesi Mecmuas, 57(3), 153-160.

Emre Yavuz D. (2011). İntramüsküler benzatin penisilin G enjeksiyonunda manüel basinç uygulamanın enjeksiyon ağrısına etkisinin değerlendirilmesi. Marmara Üniversitesi Sağlık Bilimleri Enstitüsü, Yüksek Lisans Tezi, İstanbul.

Erdoğan B. (2018). Çocuklarda kan alma sırasında uygulanan üç farklı yöntemin ağrı ve anksiyete üzerine etkisi. Atatürk Üniversitesi, Sağlık Bilimleri Enstitüsü, Çocuk Sağlığ1 ve Hastalıkları Hemşireliği Anabilim Dal, Yüksek Lisans Tezi, Erzurum.

Eti Aslan F, Badır A, Şelimen D. (2003). How do intensive care nurses assess patients' pain. Nursing In Critical Care, 8(2), 62-67.

Eti Aslan F. (2002). Ağrı değerlendirme yöntemleri. C.Ü. Hemsirelik Yüksekokulu Dergisi, 6(1), 9-16.

Das D, Grimmer K, Sparnon A, McRae S, Thomas S, Thomas B. (2005). The efficacy of playing a virtual reality game in modulating pain for children with acute burn injuries: a randomized controlled trial. BMC Pediatrics, 5(1), 1.

Gershon J, Zimand E, Pickering M, Rothbaum BO, Hodges L. (2004). A pilot and feasibility study of virtual reality as a distraction for children with cancer. Journal of the American Academy of Child \& Adolescent Psychiatry, 43(10), 1243-1249. doi:10,1097/01.chi.0000135621.23145.0532

Göksu F. (2017). Çocuklarda venöz kan alımı sırasında kullanılan sanal gerçeklik gözlügüunün hissedilen ağr1 üzerine etkisi. Bülent Ecevit Üniversitesi Sağlık Bilimleri Enstitüsü, Çocuk Sağlığı ve Hastalıkları Hemşireliği Anabilim Dalı Yüksek Lisans Tezi, Zonguldak.

Göl İ, Onarıc1 M. (2015). Hemşirelerin çocuklarda ağr1 ve ağr1 kontrolüne ilişkin bilgi ve uygulamaları. Hacettepe Üniversitesi Hemsirelik Fakülttesi Dergisi, 20-29.

Güdücü TF, Çelebioğlu A, Küçükoğlu S. (2009). Turkish children loved distraction: using kaleidoscope to reduce perceived pain during venipuncture. Journal of Clinical Nursing, 18, 2180-2186.

Gündüz S, Yüksel S, Aydeniz GE, Aydoğan RN, Türksoy H, Dikme İB, Efendiler İ. (2016). Çocuklarda hastane korkusunu etkileyen faktörler. Çocuk Sağh̆̆g ve Hastalıklar Dergisi, 59(4), 161-168. 
Kürtüncü, M., \& Davas, S. (2020). Çocuklarda kan alma işlemi sırasında uygulanan nonfarmakolojik yöntemlerin kullanım. Journal of Human Sciences, 17(2), 710-719. doi:10.14687/ihs.v17i2.5785

İnal S, Canbulut N. (2015). Çocuklarda prosedürel ağr1 yönetiminde dikkati başka yöne çekme yöntemlerinin kullanım1. Journal of Health Science and Profession, 2(3), 372-378.

İnal S., Kelleci M. (2012). Relief of pain during blood specimen collection in pediatric patients.MCN Am J Nursing, 30(6), 829-33. doi: 10.1016 / j.pedn.2015.06.007

İnal, S., Kelleci, M., (2012). Distracting children during blooddraw: looking throughdistractioncardsiseffective in pain relief of children during blood draw. International Journal of Nursing Practice, 18(2):210-9. doi: 10.1111 / j.1440-172X.2012.02016.x

İnan G. (2017). Kan alma işlemi sırasında uygulanan üç farklı dikkati başka yöne çekme yönteminin çocukların ağrı ve anksiyete düzeyine etkisi. Haliç Üniversitesi Sağlık Bilimleri Enstitüsü, Hemşirelik Anabilim Dalı, Yüksek Lisans Tezi, İstanbul.

Karakaya A, Gözen D. (2016). The effect of distraction on pain level felt by school-age children during venipuncture procedure-randomized controlled trial. Pain Manag Nurs., 17(1), 47-53. doi:10.1016/j.pmn 2015.08.005

Kearl L, Yanger S, Montero S, Morelos Howard E, Claudius I. (2015). Does combined use of the Jtip ${ }^{\circledR}$ and Buzzy ${ }^{\circledR}$ device decrease the pain of venipuncture in a pediatric population? Journal Pediatric Nursing, 30(6), 829-33.doi: 10.1016/j.pedn. 2015.06.007

Koç Özkan T, Balc1 S. (2018). Çocuklarda ağr1 kontrolünde akuprosür. Gümüsshane Üniversitesi Sağlık Bilimleri Dergisi, 7(1), 234-239.

Lobo MR., Umarani J. (2013) Cartoon distraction reduces venipuncture pain among preschoolers a quasi experimental study. IJSR - International Journal of Scientific Research, 2(6), 454-456.

Minute M., Badina L., Cont G., Montico M., Ronfani L., Barbi E., Ventura A. (2012) Videogame playing as distraction technique in course of venipuncture. Ped. Med. Chir. (Med. Surg. Ped.), 34: 77-83

Özveren H., Uçar H. (2009) Öğrenci hemşirelerin ağr1 kontrolünde kullanılan farmakolojik olmayan bazı yöntemlere ilişkin bilgileri. Sağhke Bilimleri Fakültesi Hemşirelik Dergisi, 16(3), 59-72.

Redfern R.E., Chne J.T., Sibrel S. (2018). Effects of thermomechanical stimulation during vaccination on anxiety, pain, and satisfaction in pediatric patients: a randomized controlled trial. Journal of Pediatric Nursing, 38, 1-7 doi: 10.1016 / j.pedn.2017.09.009

Semerci R. (2017). 6-12 yaş çocuklarda venöz kan örneği alırken oluşan ağrıyı azaltmada dikkati başka yöne çekme kartları ve kaleidoskop yöntemlerinin etkisi. Trakya Üniversitesi Sağlık Bilimleri Enstitüsü, Hemşirelik Anabilim Dalı Yüksek Lisans Tezi, Edirne.

Şahin M. (2013). İntramüsküler enjeksiyon uygulanan erişkin hastalarda Buzzy ${ }^{\circledR}$ uygulamasının ağr1 ve enjeksiyon memnuniyetine etkisi. Ege Üniversitesi Sağlik Bilimleri Enstitüsü, Hemşirelik Esasları Anabilim Dalı Programı Yüksek Lisans Tezi, İzmir.

Şahiner NC, Bal MD. (2016). Theeffects of three different distraction methods on pain and anxiety in children. J Child Health Care. Sep;20(3), 277-85.

Saraç H. (2018). Okul öncesi dönem çocuklarına yönelik çizgi filmlerde toplumsal cinsiyetin inşası: niloya örneği. İstanbul Üniversitesi, Sosyal Bilimler Enstitüsü, Kadın Çalışmaları Anabilim Dalı, Yüksek Lisans Tezi, İstanbul.

Schmitt YS, Hoffman HG, Blough DK, Patterson DR, Jensen MP, Soltani M, Carrougher GR, Nakamura D, Sharar SR. A randomized, controlled trial of immersive virtual reality analgesia, during physical therapy for pediatricburns. Burns, 2011, 37: 61-68.

Sülü Uğurlu E. (2017). Çocuklarda girişimsel işlemlerde nonfarmakolojik ağr1 giderme yöntemleri. Acıbadem Üniversitesi Sağhlk. Bilimleri Dergisi, 4, 198-201.

Teksöz E, Ocakçı AF. (2014). Çocuk Hemşireliği’nde sanat uygulamaları. Dokuæ Eylül Üniversitesi Hemșirelik Yüksekokulu Elektronik Dergisi, 7(2), 119-123.

Thomas S, Thomas B. (2005). The efficacy of playing a virtual reality game inmodulating pain for children with acute burn injuries: a randomized controlled trial. BMC pediatrics, 5(1), 110.doi:10.1186/1471-2431-5-1

Törüner EK, Büyükgönenç L. (2017). Çocuk Sağlığ1 Temel Hemşirelik Yaklaşımları, S: 91-10. Ankara: Nobel Tip Kitap Evleri. 
Kürtüncü, M., \& Davas, S. (2020). Çocuklarda kan alma işlemi sırasında uygulanan nonfarmakolojik yöntemlerin kullanım. Journal of Human Sciences, 17(2), 710-719. doi:10.14687/ihs.v17i2.5785

Yayan EH, Zengin M. (2018). Çocuk kliniklerinde terapötik oyun. Gümü̈shane Üniversitesi Sağhlk Bilimleri Dergisi, 7(1), 226-233.

Yıldız T. (2014). Çocuklarda intramüsküler penisilin enjeksiyonu ağrısına lokal buz uygulamasının etkisi. Haliç Üniversitesi Sağlık Bilimleri Enstitüsü, Hemşirelik Anabilim Dalı Yüksek Lisans Tezi, İstanbul.

Yoo H, Kim S, Hur HK, Kim HS. (2011). Theeffect of an animation distraction intervention on pain response of preschool children during venepuncture. Applied Nursing Research, 24(2), 94-100. doi:10.1016/j.apnr.2009.03.005

\section{Extended English Summary}

Abstract thinking and cause and effect ability in children are different individuals than adults and who have special care needs and who have limited ability to cope with stressful life events because their life experiences, mental development and their ability to express themselves verbally are insufficient. The hospital environment is frequently used for follow-up from the birth of the child or during diseases, and painful medical procedures such as blood collection, injection and vaccination are performed. Invasive procedures in the hospital environment cause pain, anxiety, fear and psychosocial changes for children.

Considered as the fifth finding of life, pain is a complex, multi-faceted experience that combines subjective, psychological aspects and is influenced by physical, emotional external factors. The perception of pain varies among people, and may even change over time in the same person. One of the most experienced groups in this complexity is children who cannot express themselves. The pain experienced by children affects their physical, hormonal, mental and social development, the experiences of parents and other people in the family, the nutrition and excretory system, and causes psychosomatic disorders, fear of medical procedures and disruption of treatment.According to Erikson theory; It is stated that childhood experiences have a permanent effect on future personality traits.In one study, it was stated that approximately $40 \%$ of adults refused to take blood samples because of fear of injection.

The American Academy of Pediatrics (AAP) and the American Society of Pain (APS) recommend that stress and pain be minimized, even in invasive procedures such as vascular access. According to the World Health Organization (WHO), pain relief is the most fundamental right. Relieving the pain of children and improving the quality of life is one of the main goals of nursing care. In 1989, Donna Wong described pain control as a fundamental principle in the philosophy of atraumatic care.

Pain control in children is team work. The points that distinguish the nurse from other team members and make them important in pain control; The nurse is together with the patient for a long time, learning the patient's previous pain experiences and methods of coping with pain, benefiting from these when necessary, teaching the strategies to cope with pain, applying the planned treatment, monitoring the effects and results, providing an empathic approach. To reduce the effects of nurses' pain associated with invasive interventions in children; they need to be able to manage pain effectively to relieve their physical and emotional effects. When planning the management of pain, the type, location, severity of the pain, the characteristics of the disease, the patient's age, physical condition and medical possibilities should be carefully examined and the appropriate method should be chosen.

In children, pharmacological and non-pharmacological methods are used to reduce pain during medical procedures. Pain control with drugs is the most commonly used treatment method because it acts quickly and is easy to apply. However, pharmacological drugs used during invasive procedures cause vasocontriction, decrease success in vascular access, prolong the duration of the procedure and cause harm to the body.Non-pharmacological methods provide relief of pain by increasing the release of endorphins, the body's natural morphine, and have no adverse side effects. 
Non-pharmacological methods are non-invasive, inexpensive, reliable, have no side effects and are independent nursing practices. Non-pharmacological methods; supportive methods (psychosocial), physical methods and cognitive/behavioral methods. Supporting methods; This includes techniques such as watching videos, reading books, and being with the family during the process. Physical methods include; applications such as hot-cold application, positioning, buzzy device positioning. Cognitive/ behavioral methods; pain, perceptual, sensory, behavioral dimension and includes relaxation, distraction, hypnosis.

Pubmed, Scopus, Google Scholar, EBSCOhost, ScienceDirect, Yök Thesis search engines, " pain, anxiety, fear, blood taking, children " keywords are written in English and Turkish, without any date limitation studies. Studies on pain management during the blood collection process in children have increased in recent years and there are 2 doctoral theses and 12 master theses in NTH National Thesis Center. In recent years, the use of non-pharmacological methods related to acute pain reduction in pediatric age groups in our country has started to attract attention and more studies are needed to be accepted in nursing.

Studies have shown that nonpharmacological techniques applied during the blood collection process reduce the anxiety, fear and pain in children and increase the satisfaction of the family and child in nursing care and compliance with the medical procedures, and positively affect the short and long term results due to the fear of medical procedure. It is thought that the use of these methods in children during blood collection should be expanded. 